\title{
Elevada prevalência de blastocistose em pacientes do Centro de Saúde de Soledad, Estado Anzoátegui, Venezuela
}

\author{
Blastocystosis: a high prevalence of cases found in patients from \\ Health Center of Soledad, Anzoategui State, Venezuela
}

\section{Virma Velásquez ${ }^{1,2}$, Rixcia Caldera ${ }^{2}$, Wladimir Wong ${ }^{2}$, Gloria Cermeño ${ }^{2}$, Maximo Fuentes ${ }^{2}$, Ytalia Blanco $^{1,2}$, Maria Aponte ${ }^{1,2}$ e Rodolfo Devera ${ }^{1,2}$}

\section{RESUM0}

Entre 98 exames parasitológicos de fezes de pacientes do Centro de Saúde de Soledad, Anzoátegui, Venezuela, foram encontrados 46 (46,9\%) positivos para Blastocystis hominis.

Palavras-chaves: Blastocystis hominis. Blastocistose. Pacientes. Venezuela. Prevalência.

\begin{abstract}
The parasitological examination of fecal samples from 98 patients from an Ambulatory Health Center of Soledad, Anzoategui, Venezuela revealed a rather high proportion of results positive for Blastocystis hominis ( $46.9 \%$ ).
\end{abstract}

Key-words: Blastocystis hominis. Blastocystosis. Patients. Venezuela. Prevalence.

Blastocystis hominis é um dos protozoários mais freqüentemente encontrados no exame parasitológico das fezes. Existem várias controvérsias, sobretudo referentes à epidemiologia, à transmissão, aos aspectos clínicos e à patogenicidade do parasita $^{17}$. Com relação ao diagnóstico, também se tem dificuldades, pois ainda que se saiba 0 exame direto é a melhor técnica. Alguns centros não fazem o diagnóstico devido a diferentes causas, tais como falta de conhecimento do pessoal, uso da técnica incorreta ou simplesmente não concedem importância a seu achado ${ }^{18}$.

A taxonomia do parasita também é indefinida. Em 1996, estudos mediante análise filogenética do RNA ribossomal, incluíram o parasita dentro dos Stramenopiles, um complexo grupo de protozoários ${ }^{18}$. Mais recentemente, essa observação preliminar foi confirmada utilizando-se dados de sequências moleculares múltiplas ${ }^{3}$.

Embora seja um protozoário polimórfico, se descrevem quatro formas principais: vacuolar, granular, amebóide e 0 estágio de cisto. A primeira é a mais freqüentemente observada nas fezes, sendo, portanto, a utilizada para fazer 0 diagnóstico ${ }^{8}$.
0 objetivo do estudo foi determinar a prevalência de B. hominis em pacientes atendidos no Posto de Saúde de Soledad no Estado Anzoátegui, na Venezuela, no período março-agosto de 2003. A comunidade é de tipo rural, localizada na margem esquerda do rio Orinoco. Em geral, o padrão de vida é considerado como baixo.

As amostras fecais recebidas foram preservadas em formol a 10\% e avaliadas dentro das 48 horas seguintes mediante a técnica de sedimentação espontânea² ${ }^{2}$ Para verificar a morfologia do protozoário, as amostras positivas foram avaliadas novamente um mês depois.

Foram estudadas amostras de 98 pacientes, sendo a maioria (67,3\%) menores de 10 anos. Amédia de idade foi de 12 anos com desvio padrão de 17,1 anos, e 52\% eram do sexo feminino e 48\% do masculino. A prevalência de parasitoses intestinais foi de 58,2\% (57/98). A maioria dos infectados estava na faixa etária de 0 a 9 anos, embora essa diferença não tenha sido significativa $\left(\chi^{2}=3,71\right.$; g.l. $=5 p>0,05)$. Ambos os sexos foram igualmente afetados ( $p>0,05)$. Foram encontrados 46 (46,9\%) Blastocystis hominis, $13(13,3 \%)$ Entamoeba coli, 11 (11,2\%) Endolimax nana,

\footnotetext{
1. Grupo de Parasitosis Intestinal, Departamento de Parasitologia y Microbiología, Escuela de Ciências de la Salud, Universidad de Oriente, Ciudad de Bolívar, Estado Bolívar, Venezuela. 2. Ambulatório Rural Tipo II, Soledad, Estado Anzoátegui, Venezuela.

Endereço para correspondência: Dr. Rodolfo Devera. Dpto de Parasitologia y Microbiología, Escuela de Ciencias de la Salud, Universidad de Oriente. Núcleo Bolívar. Av. José Méndez, Barrio Ajuro, Ciudad Bolívar, Estado Bolívar, 800-1A, Venezuela.

Fax: 00286 632-4608

e-mail: rodolfodevera@hotmail.com

Recebido para publicação em 21/3/2005

Aceito em 21/5/2005
} 
7 ( 7,1\%) Giardia lamblia, 2 (2\%) Iodameba butschlii, 3 (3,1\%) Trichuris trichiura e 3 (3,1\%) Ascaris lumbricoides.

Essa prevalência, e particularmente de B. hominis, coincide com a encontrada em comunidades rurais vizinhas ${ }^{92}$, sendo uma das maiores da Venezuela ${ }^{92}{ }^{17}$. Em outras localidades de América Latina, também se tem assinalado elevadas prevalências de blastocistose 411131416 .

Apesar da fragilidade das formas vacuolares ${ }^{8}$, a preservação em formol a 10\%, e posteriormente exame pela técnica de sedimentação espontânea dentro das 48 horas seguintes, mostrou resultados adequados. A preservação por mais de um mês, após a coleta, determina que as formas vacuolares se deformam, dificultando a identificação.

Blastocystis hominis deve-se assinalar como o responsável pelas manifestações clínicas em todo paciente com: 1) B. hominis numerosos na amostra fecal. Sugere-se que mais de 5 células por campos de 400X se associa com sintomas em muitos pacientes. 2) Presença de formas vacuolares grandes nas fezes. 3) Ausência de outras causas que expliquem a sintomatologia. 4) Eliminação dos sintomas apos tratamento antiparasitário específic $0^{8}$. Como é difícil cumprir com todos esses critérios, consideramos sugestivas a exclusão de outras causas e a cura clínica e parasitológica do paciente, logo após o tratamento.

A água poderia ser 0 principal veículo de contaminação da maioria dos protozoários ${ }^{15}$, pois esta comunidade tem deficiente fornecimento de água potável, além do nível educativo que leva a baixas condições de higiene e dos limitados recursos econômicos que se tem verificado na comunidade. Tudo isto forma parte da chamada etiologia social das parasitoses intestinais ${ }^{5}$.

\section{REFERÊNCIAS BIBLIOGRÁFICAS}

1. Amato Neto V, Alarcón RSR, Gakiya E, Bezerra RC, Ferreira CS, Braz LMA. Blastocistose: controvérsias e indefinições. Revista da Sociedade Brasileira de Medicina Tropical 36: 515-517, 2003.

2. Amato Neto V, Corrêa LL. Exame parasitológico das fezes. Editora Sarvier, São Paulo, 1991.

3. Arisue N, Hashimoto T, Yoshikawa H. Phylogenetic position of Blastocystis hominis and Stramenopiles Inferred from Multiple Molecular Sequence Data. Journal of Eukariotic Microbiology 49: 42-53, 2002.
4. Borda CE, Rea MJ, Rosa JR, Maidana C. Intestinal parasitism in San Cayetano, Corrientes, Argentina. Bulletin of Pan-American Health Organization 30: 227-233, 1996.

5. Botero D. Persistencia de parasitosis intestinales endémicas en América Latina. Boletín de la Oficina Sanitaria Panamericana 90: 39-37, 1981.

6. Chacín-Bonilla L. El problema de las parasitosis intestinales en Venezuela. Investigación Clínica 31: 1-2, 1990.

7. Devera R. Blastocystis hominis: 0 enigma continua. Revista da Sociedade Brasileira de Medicina Tropical 31: 491-492, 1998.

8. Devera R. Blastocystis hominis parasita intestinal pouco estudado no Brasil. Jornal Brasileiro de Medicina 76: 85-89, 1999.

9. Devera R, Cermeño, Blanco Y, Bello Montes MC, Guerra X, De Sousa M, Maitan E. Prevalencia de blastocistosis y otras parasitosis intestinales en una comunidad rural del Estado Anzoátegui, Venezuela. Parasitología Latinoamericana 58: 95-100, 2003.

10. Devera R, Requena I,Velásquez V, Castillo H, Guevara R, Silva M, Sousa M, Marín C. Balantidiasis en una comunidad rural del estado Bolívar, Venezuela. Boletín Chileno de Parasitología 54: 7-12, 1999.

11. Kobayashi J, Hasegawa H, Forli A, Nishimura N, Yamanaka A, Shimabukuro T. Prevalence of intestinal parasitic infection in five farms in Holambra, São Paulo, Brazil. Revista do Instituto de Medicina Tropical de São Paulo 37: 13-18, 1995.

12. Machuca J, Gimenez G. Blastocystosis intestinal en niños de 1 a 12 años. Evaluación Clínico-Parasitológica. Municipio Independencia (Estado Anzoátegui) . 1996-1997. Tesis de Grado, Universidad de Oriente, Ciudad Bolívar, Venezuela, 1997.

13. Mejías G. Infecciones enteroparásitarias en escolares rurales del Archipielago de Chiloe, X Región, Chile. Boletín Chileno de Parasitologia 48: 28-29, 1993.

14. Mercado R, Otto JP, Musleh M, Pérez M. Infección humana por helmintos y protozoos intestinales en Calbuco, X región, Chile, 1997. Boletín Chileno de Parasitología 52: 36-38, 1997.

15. Organización Mundial de la Salud. Infecciones intestinales por protozoos y helmintos. Editora Gráficas Reunidas, Serie informes técnicos 666, Ginebra, 1981.

16. Otto JP, Musleh M, Pérez R, Mercado R. Enteroparasitosis en 40 grupos familiares de la localidad de Chauquear, isla Puluqui, X Region de Chile, 1997. Parasitología al Día 22: 3-11, 1998.

17. Ramos L, Salazar-Lugo R. Infestación parasitaria en niños de Cariacoestado Sucre, Venezuela y su relación con las condiciones socieconómicas. Kasmera 25: 175-189, 1997.

18. Silberman JD, Sogin ML, Leipe DD, Clark CG. Human parasite finds taxonomic home. Nature 380: 398, 1996. 